\title{
CREATIVE PORTFOLIO STRATEGY AS A MODEL OF MANAGEMENT IN MEDIA COMPANY: AN EXAMPLE OF PUBLIC BROADCASTING
}

\author{
Biljana RATKOVIĆ-NJEGOVAN ${ }^{1}$, Dušan ĐURAŠKOVIĆ, Branislava KOSTIĆ ${ }^{2}$ \\ University of Novi Sad, Faculty of Technical Sciences, Department of Industrial Engineering and Management, Novi \\ Sad, Republic of Serbia. Corresponding author. E-mail: biljananj@ neobee.net \\ University of Novi Sad, Faculty of Technical Sciences, Department of Industrial Engineering and Management, Novi \\ Sad, Republic of Serbia.
}

Accepted 13 October, 2011

\begin{abstract}
This paper deals with issues of functioning public media companies in the context of new technological possibilities of communication media and a keen commercial competition. A creative and dynamic portfolio has been proposed as a possible model of business strategy. For a media organization that means the transition from traditional to modern business concept, which involves researching the characteristics, processes, challenges and impact of the portfolio of media products. Special attention is given to the balance of the portfolio and orientation on the quality of the content of media products.
\end{abstract}

Keywords: media, management, portfolio, public service broadcasting.

\section{INTRODUCTION}

It is generally accepted that public media is at "an inflection point" and disrupted traditional balance (BBC, 2010), so in the following years broadband must adapt to challenges and possibilities brought by digital age. The expansion of services through multiple channels and platforms offers more choice of programs, increases the diversity of content and improves the availability of both existing and new services. In the light of the new opportunities that the Internet provides, public media has a strong chance to expand its mission and values for this new medium.

It is not only imperative for development of electronic architectures the one imposed by new action strategies of Public Service Broadcasting regarding the overall organization of work commercial, journalistic and economic practices (Lawson-Borders, 2006), but also increasing criticism of the commercial communication directed to public broadcasters for exceeding the powers of public media. Commercial media competitors openly ask the doctrinal question of legitimacy of public broadcasting, arguing that the regulated public media systems emerged in the period of the media spectrum scarcity, which are now obsolete, and that their monopoly position provides an unfair competitive advantage.

There are, however, optimistic predictions about the future of Public Service Broadcasting (Jakubowicz, 2006) since the "unlimited" offer from commercial broadcasters is not realistic and the positioning of new media organizations that would attract such a large audience is always a slow and difficult process. Collins et al. (2001) states that PSB must have its position in this century as well, but the nature of this position will depend on the strategy chosen by PSB itself and the corresponding support from the government, then on the strength of public broadcasters to conduct technological changes and the quality of programme choice capable to withstand the pressure from commercial competitors.

Therefore, the management of public media companies are to define a strategy to maintain the principles of public service in communication with the audience, organizational adaptation to service convergence and creating the content useful for the community. 


\section{BALANCE: SETTING THE BOUNDARIES}

Public Service Broadcasting must orientate towards audience universality (Collins et al, 2001) - mass and fragmented, offering the contents which may not be profitable. Hence the traditional model of PSB ought to be examined, which means the following: a) overcoming a critical issue of ratings as the only form of audience measurement; b) accepting nonstandardized audience measurement; c) introducing the offer of non-linear programmes; d) allowing a larger number of channels; e) delivering newer productions and services through a wide network (Ratković-Njegovan and Radenković, 2010).

Here a question is arising, and this is what combination of new media activities may maintain the mission of public Radio Television of Vojvodina in the long-term period. Clearly, the answer to this question cannot be provided easily. Jakubowicz (2006) thinks that there is not the proper strategy, and if there is one, its success is unlikely. That is why it is perhaps more opportune to discuss the dimension of evaluating PSB, which includes quality, reliability and credibility, innovativeness, diversity, social impact, audience share. Van Meurs et al. (2006) adds reach, cost efficiency and effectiveness.

In the digital age, with no natural restrictions on the transfer of media content, it is easy to lose focus regarding the width of the portfolio of media products, and the lack of real vision and strategy can lead to deterioration in the quality and loss of identity of PSB. Hence it is necessary to put emphasis on product quality according to the principle the less, the better. The essence of this compromised attitude is based on the fact that, despite the large number of broadcasting channels and excess of offer and repetitions, the right information today is really rare.

On the one hand, this means that public broadcasters are not required to produce all the types defined by the Law on Broadcasting, so if something is unattainable for the national broadcaster in terms of quality and price - it can be bought from other broadcasters. On the other hand, the other questions remain open: what information services should be offered as public services; what are the strategic functions of multi-platform participation of PSB, should public service, and to what extent, develop individualized services (DG Competition, 2004); how to charge?

\section{PORTFOLIO DEVELOPMENT}

Faced with tough competition and cultural, political and economic struggle for the attention of the audience, PSB should change fast their oldfashioned, patriarchal and elitist position (Murdock, $2005)$ and modernize radically.

New opportunities for development perhaps lie in diversification and portfolio development. Media companies might either expand their business beyond the traditional media areas into new media, or they might build up a portfolio of different media products to complement their offerings (Achtenhagen, 2005). The fact is that traditional media product, designed to the requirements of the mass audience, loses its effectiveness due to the transformation of the market into fragmented segments. Traditional media products are facing maturing or declining stage of its life cycle.

Therefore it is necessary to focus on four areas of activity of media organizations: portfolio entrepreneurship, dynamic processes, flexible organization and inspired leadership (MoserWellman, 2007). Intensive orientation of media organizations to portfolio strategy is conditioned by the following reasons: diversity of programme, increase in the number of business areas and their diversification, the need for simultaneous development of new business concepts and new communications products, investing in services and media products in the market rise. Portfolio strategy is based on the model of prediction; it refers to the high business risk and experimentation, so necessarily involves the readiness to respond to losses by new quick attempts (risk culture). This entrepreneurial orientation requires dynamic internal and external processes and development of innovations at all levels, bearing in mind the following imperatives: create a business development function; fixate on the consumer; revisit and adapt the business strategy; invest in technology; have dynamic relationships with the public; create flexible organizational structures, recursive and self-transformative organization (Moser-Wellman, 2007).

\section{THE QUALITY OF THE CONTENT, ABOVE ALL}

Innovations in the field of audiovisual media are most evident in the production, design, method of delivering media content and the interaction with clients. In virtually unlimited participatory and interactive multi-channel environment, it is 
necessary to create programmes of high quality and deliver them most efficiently. The quality of content is an essential element of attraction and the most important element of credibility of a program.

The orientation to Public Service Content, or new media content over technology, means investment in supply not in demand (Lopes, 2005). A television channel's programming should be conceptualized as assets and optimized as product portfolio (Litman et al., 2000). Unlike financial portfolio, where risk reduction and profits from the total portfolio of investments are in the focus of their creation and management, in the case of media products of PSB the accent must be on creating information as the public and general "communication good" (McQuail, 2003). To achieve the principles of efficiency and effectiveness in achieving its vision and strategy, the management of PSB must choose the products for its media portfolio that are of great value for the audience, make a significant contribution to the company in fulfilling its social function and have relatively low investment and operating costs.

When creating its portfolio, a media company chooses one of the generic strategies of diversification. Sjurts (2002) lists the following: a) intramediary diversification refers to vertical diversification into prior or later value chain activities within the same media industry; b) intermediary diversification can take place into related, unrelated or converging media industries and might reduce the threat of substitutes in customer or advertising markets; c) extramediary industries not related to media. There are numerous internal and external factors contributing to the decision on the choice of generic strategy such as: availability of resources, market possibilities, development trends, personal preferences of managers, etc. However, it seems that it is crucial to select the desired market segment where we want to do business.

Conversely, introducing portfolio products into the offerings of a company imposes conceptual and pragmatic changes within the company itself. Diversification beyond the first product can be viewed as an entrepreneurial process, resources need to be acquired of crucial importance here are entrepreneurial and strategic thinking skills as well as the financial resources needed to finance the product launch (Achtenhagen, 2005). As the size of product portfolio is getting bigger, some significant changes may be necessary within the company's strategy, organization and administration as well as in the activities for the development of products, marketing and services oriented towards clients (Picard, 2005). Figure 1 shows the relationship of portfolio management with other key elements of the organization. The focus is on creating values for a client / audience. The value makes other processes work. All other internal and external activities of the company must be subordinate to vision, mission, strategy, portfolio management and entrepreneurial management (Figure 1).



Figure 1: This representation of the corporate environment as a planetary gear shows customer value as the central driver (Mello et al., 2006)

The portfolio strategy implemented by a company must be elaborated so that it considers all market opportunities and neutralizes current threats or foreseen threats. At the same time the company must 
value its strong points, by referring to the competition. It is based on an optimal combination of three key elements of each portfolio: portfolio balance, attractiveness of market segment and potential synergy between products and market (Johnson and Scholes, 2002). The concept of synergy is related to the terms of economy of scale and economy of scope, and it is based on the assumption that certain products may have a better result in coordination with other products from the portfolio than independent business units may have (Campbell and Luchs, 1992).

The strategy is based on the growth as a component defining the direction of the company's future performance, on competitive advantages, and on strategic flexibility. This matrix includes planning of resources and investments, and analysis of prices and quality competitiveness. The analysis can suggest which activities should be eliminated and which retained and possibly developed later on (Todorovic, 2003). More radical interpretations of portfolio strategy are based on the concept of agressive growth of media companies' income and modifying the strategy from being bottom-line to top-line.

In portfolio analysis of media organizations we observe only businesses that can be called strategic units, which in the case of PSB includes news and educational programming, local programme, formats conformed to national requirements, children's programme (niche products), programme for minorities, older and poorer population, all in accordance with the marketing tribal strategy (micro-niche products). The analysis leads to real facts which products should be kept and which should be eliminated, in which products we should invest more or less and which new products should be developed.

\section{CONCLUSION}

In this conceptual-descriptive text we appeal for the survival of public media, in terms of their defined roles to inform, educate and provide entertainment for citizens by their original content, and also to enable them to meet a wide range of their needs, under the motto: people must feel that PSB is theirs.

Such strictly set requirements impose a business strategy formulated in the way that each product contributes to the social role of PSB and values for audience. In other words, this refers to devotion to quality, aesthetic and ethical values as well as for popularity.
PSBs are large and structurally complex pyramid organizations with a long European experience (over 80 years), and all have gone or are going through the phases of evolutionary flow from monopoly, managed economy, multichanel and multimedia to fully digital (Suter, 2005).

Strategic behaviour directed to the dynamic portfolio requires an integration of competencies, hierarchies, strategies and tactics (Mello et al., 2006). Management of media organizations must flexibly and responsively adjust its portfolio concerning the following:

- Organizational structure;

- Offer of media content;

- Orientation to both massive and fragmented (strategy of differentiation);

- Orientation to three most important technological and communication domains: digital, diversity and dialogue.

The key to the selection of product that contributes to sustainable business is in what serves as a high value for a media consumer. The fundamental problem lies in the criteria for selection and evaluation of effects of products and portfolio as a whole. Everything indicates that the measure unit of success is a value for audience. The challenge is how to reliably materialize the value so quantitative analyses of performances can be conducted.

\section{REFERENCES}

Achtenhagen, L. (2005). Media Portfolio Development: Strategic and Organizational Challenges. In Picard, R. G. (Ed.), Media Product Portfolios: Issues in Management of Multiple Products and Services (pp.33-48). Mahwah, New Jersey London: Lawrence Erlbaum Associates Publishers.

BBC. (2010). BBC Strategy Review. London: BBC Trust.

Campbell, A., \& Luchs, K. (1992). Strategic synergy. Oxford: Butterworth/Heinemann.

Collins, R., Finn, A., McFadyen, S., \& Hoskins, H. (2001). Public Service Broadcasting Beyond 2000: Is There a Future for Public Service Broadcasting? Canadian Journal of Communication, 26(1), 3-15.

Jakubowicz, K. (2006). Public service broadcasting: a new beginning, or the beginning of the end? Presentation for the RIPE@2006 Conference: "Public Service Broadcasting in the Multimedia Environment: Programmes and Platforms".

Johnson, G., \& Scholes, K. (2002). Exploring corporate strategy (6th ed.). Essex: Pearson Education.

Lawson-Borders, G.L. (2005). Media Organizations And Convergence: Case Studies of Media Convergence 
Pioneers (Lea's Communication Series). Lawrence Erlbaum Associates.

Litman, B., Shrikhande, S., \& Ahn, H. (2000). A portfolio theory approach to network program selection. Journal of Media Economics, 13(2), 57-79.

Lopes, M. (2005). Audiovisual e interesse público. Actas do III SOPCOM, VI LISOCOM E II IBérico Volume III. Portugal.

McQuail, D. (2003). Public Service Broadcasting: Both Free and Accountable. The Public/Javnost, 13-28.

Mello, S., Mackey, W., Lasser, R., \& Tait, R. (2006). Value Innovation Portfolio Management. Fort Lauderdale: J. Ross Publishing.

Moser-Wellman, A. F. (2007). Running While the Earth Shakes. Creating an Innovation Strategy to Win in the Digital Age: A Study on Innovation in the News Media. Northwestern University Media Management Centre.

Murdock, G. (2004). Building on the Digital Commons: Public Broadcasting in the Age of the Internet. The 2004 Spry Memorial Lecture, University of Montreal, Vancouver 18 Noovember 204/Montreal, 22 November 2004.
Picard, R.G. (2003). Cash cows or entrec te: publishing companies and new technologies. Trends in Communication, 127-136.

Picard, R.G. (2005). The Nature of Media Product Portfolio. In Picard, R. G., Media Product Portfolios: Issues in Management of Multiple Products and Services (pp. 1-17). Mahwah, New Jersey: Lawrence Erlbaum Associates Publishers.

Ratković Njegovan, B. \& Radenković, V. (2010). Management in the Public Broadcasting Service: The reasons for a change of strategy. International Journal of Industrial Engineering and Management (IJIEM), 1 (2), 69-76.

Sjurts, I. (2002). Straegien in der Medienbranche Grundlagen und Fallbeispiele (2nd. ed.). Wiesbaden: Gabler.

Todorovic, J. (2003). Strategijski menadžment [Strategic Management]. Belgrade: Faculty of Economy.

Van Meurs, L.D. (2006). Mapping programme quality: Evaluating the quality of television programmes using an online Appreciation Panel. Paper for the RIPE@2006 Conference, the Netherlands, November (pp.16-18). 